\title{
A STUDY OF INCIDENCE OF POULTRY DISEASES AND DISEASE CONDITIONS CAUSING MORTALITY IN COLOMBO REGION
}

\author{
U. G. J. S. WICKRAMASURIYA* \\ Veterinary Investigation Centre, Welisara, Sri Lanka. \\ (Date of receipt : 19 February 1982) \\ (Date of acceptance : 02 May 1985)
}

\begin{abstract}
This paper describes the incidence of poultry diseases and disease conditions recorded at the Veterinary Investigation Centre, Welisara, during the period 1975 to 1979 . It was observed that the incidence of diseases like Pullorum Disease, Chronic Respiratory Disease, Fowl Typhoid andEncephalomalacia declined Conditions such as Coccidiosis, Chills, Ascaridiasis, Pneumonia, Enteritis, Colibacillosis, and Visceral Gout had variable incidence throughout the period. Incidence of Lymphoid Leucosis, Marek's Disease, Ranikhet Disease, Omphalitis, Infectious Coryza, Aspergillosis and Salt Poisoning were steadily increasing.
\end{abstract}

\section{Introduction}

A number of poultry diseases in Sri Lanka have been reported by several workers. $1,2,4,5,6,7,8,9,10,11,12,13,14$ Kulasegaram $^{5}$ studied the incidence of diseases of poultry in Sri Lankafor a period from 1960 to 1974 based on investigations carried out on poultry carcasses received at the Veterinary Research Institute at Peradeniya. The present study gives the incidence of diseases in. poultry for a period of five years from 1975 to 1979 based on investigations carried out at a regional level, at the Veterinary Investigation Centre (VIC.), Welisara. This centre is situated in the Western Region of the country, covering the districts of Colombo and Gampaha. In this area, organised poultry farming is based to a large extent on the deep litter system of management. When confronted with diseases leading to mortality, farmers call at the VIC with the carcass of a dead bird for diagnosis and obtain necessary advice for treatment and control of the condition. At this centre an average of 200-300 autopsies were carried out each year during the period of study.

\section{Materials and Methods}

Poultry carcasses received at the VIC were subjected to detail examination. In each instance, a detail history of the affected flock was obtained relating to symptoms, clinical signs, mortality, morbidity pattern, history of

\footnotetext{
* Present address: Veterinary Department, Colombo Municipal Council, Maligakanda, Colombo 10.
} 
vaccinations, and treatment. A diagnosis of the disease condition was made on lesions seen at autopsy and laboratory tests where possible. The background history relating to the flock was also taken into consideration. As the recordings were made mainly on examinations of poultry carcasses, the incidence recorded were conditions causing mortality and such conditions like Avitaminosis and Fowl Pox could not be represented well.

In confirming the diagnosis, available laboratory tests were done. When Coccidiosis were suspected, on typical lesions on intestine, a scraping was taken from intestinal mucosa and examined under the microscope for the relevant stages of development of the coccidia.

In Pullorum Disease when typical lesions were seen, the Rapid Slide Test was done from blood drawn from the heart. Also, Salmonella organisms were isolated by culturing from swabs taken from the intestine, on MacKonkey agar and 'stabing' the white colonies on Triple Sugar Iron medium. Black colouration in the butt shows $\mathrm{H}_{2} \mathrm{~S}$ production to presence of Salmonella organisms and Proteus spp. Proteus was eliminated by Urease Test. Typing was not done as specific antisera were not available.

Chronic respiratory Disease due to Mycoplasma gallisepticam was suspected on typical lesions on air sacs, lungs, trachea, sinuses and on visceral organs. Also, clinical signs, symptoms, pattern of disease and history of flock were taken into consideration. It was seen mostly in flocks of adult birds reared on damp litter.

Diagnosis of cases of Chills were established from the presence of typical distension of gall bladder along with congestion of lungs, sometimes with nephritis. Also, the history of the flock was taken into consideration.

Lymphoid Leucosis was suspected on typical post mortem lesions. and history of the flock.

Ascaridiasis was diagnosed on the presence of Ascaridia adult stage.

Marek's Disease was suspected on typical post mortem lesions and clinical signs of leg weakness, distension of crop, dropping of feathers due to skin lesions, etc.

Ranikhet Disease was suspected on pathognomic post mortem lesions like pinpoint haemorrhage in proventriculus, necrotic patches on intestines. among other lesions and history including symptoms. 
Fowl Typhoid was suspected on typical pathognomic lesions such as bronze colouration and enlargement of liver among other lesions. Salmonella organisms were isolated on Mackonkey agar but no typing of the species was done due to non-availability of antisera.

Omphalitis is a pathological condition due to infection of yolk sac with a variety of organisms found in the environment. A normal yolk sac is absorbed $24-48$ hours after hatching. An infected yolk sac is seen for sometime after hatching.

Infective Coryza was established when mucoid nasal discharge sometimes with swelling of eyelids, pasting of eyelids and cheesy materials between the eyelids. No other organ was affected. Direct smears and sometimes culture on blood agar, Gram negative rods were seen.

When Aspergillosis was diagnosed, a white nodule or a concave disc was cultured on Sabouraud Medium. After 24 hours abundant growth was seen. The fungus was identified under microscope.

Encephalomalacia due to low vitamin $\mathrm{E}$ feed was established on typical 'bicycling' movements of the legs. In all cases vitamin E was introduced to feed and the spread of the disease was arrested.

Colibacillosis was diagnosed on typical characteristic lesion where the heart is covered with a gelatinous mass under the pericardium due to fibrinoid pericarditis. The affected birds were $4--6$ months of age mostly with a complaint of losing one or two birds a week. In such cases Escherichia coli was isolated on Mackonkey Agar. ${ }^{3}$

Salt Poisoning was established when there was generalised oedema of the carcass with history of giving ration high in common salt. The most common source was addition of powder residue of dry fish as a source of fish meal.

\section{Results and Discussion}

A total of 49 conditions were recorded during the five year period from 1975 to 1979. The number of conditions recorded each year is shown in Table 1.

Table 1. - No. of autopsies and no. of conditions recorde"d

\begin{tabular}{lrrrrr} 
& 1975 & 1976 & 1977 & 1978 & 1979 \\
\hline No. of autopsies & 198 & 297 & 220 & 304 & 195 \\
No. of conditions & 31 & 40 & 30 & 30 & 29 \\
\hline
\end{tabular}


The percentage incidence of each condition per year and the average of these percentages for five years were determined as shown in Table 2. On this, the incidence of diseases were classified as (1) High ( $5 \%$ to $12 \%$ ), (2) Moderate (3\% to $5 \%$ ), (3) Low (1\% to $3 \%$ ) and (4) Very Low (below $1 \%$ ).

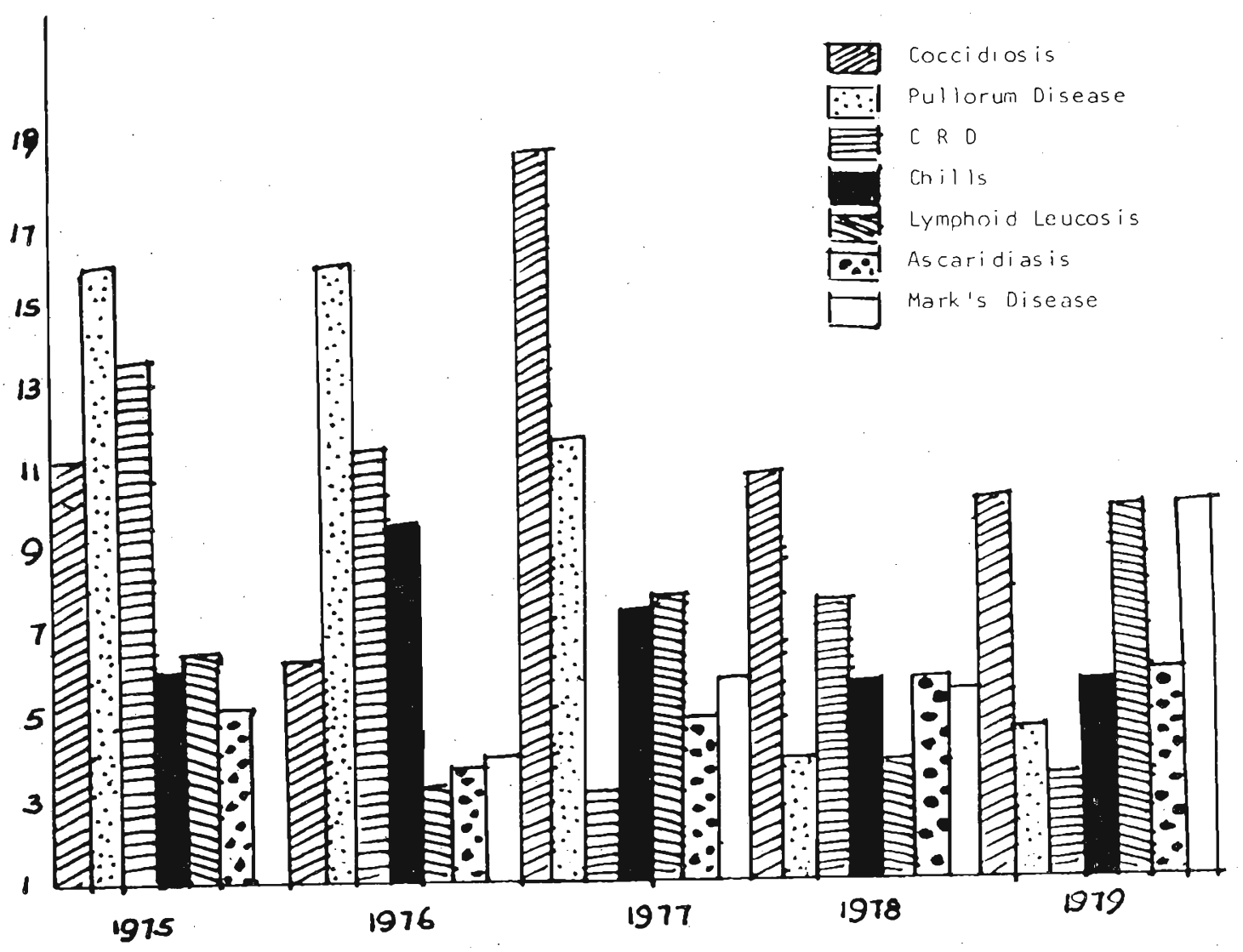

Fig. 1. Diseases of High Incidence. 


\subsection{Diseases and Disease Conditions of High Incidence}

Figure 1 shows the distribution. Coccidiosis recorded the highest average incidence during the five year period (Table 2). Its incidence was high throughout the period and was the highest in 1977, 1978 and 1979. This seems to be the general pattern of the disease in this country since $1960 .^{5}$ However incidence recorded by Kulasegaram is slightly higher (average incidence $15.3 \%$ ) and this may be due to climatic differences of the two regions compared. A limitation for control of Coccidiosis was referable mainly to non-availability of variety of effective coccidiostats in the market. The most commonly used Coccidiostat was Zoalene and this too was not available all the time during this period.

Pullorum Disease had the second highest incidence. It was observed that the incidence was quite high in 1975, 1976 and 1977, giving as high as $16.2 \%$ in 1975 and gradually going down to $4.6 \%$ in 1979 . Due to a very high demand for day old chicks, a large number of small time hatcheries opened up during the early seventies. Due to poor management levels in such small holdings, there was high incidence of the disease and later with some experience in hatchery hygiene such conditions were brought under control. This condition was one of the major conditions causing high mortality of day old chicks in the first few weeks of life. It responded well to treatment with Furazolidone combined with Chloramphenicol.

Chronic Respiratory Disease due to Mycoplasma gallisepticum comes third highest average incidence during the period of study. It was seen mostly in adults and growing birds, especially during the rainy seasons in poultry houses which are not well protected against rain. Once the disease has set in, it was difficult to control. More effective drugs such as tylosin (Tylan-Elli Lilly) and Spiramycin (M \& B) were not imported to the country during the period of study.

Deaths due to chills during the first few weeks of life was quite a problem and it caused heavy mortality and was due to bad management practices. Though the average incidence recorded was $7.2 \%$, it was below this since 1978.

Lymphoid Leucosis had the fifth highest average and there was a tendency for increase since 1979 with an incidence of $10.3 \%$.

Incidence of Ascaridiasis appears to be quite uniform during the period of study as was observed by Kulasegaram. ${ }^{5}$ This was probably due to a dynamic equilibrium that has been reached at the present level of manage- 
ment, environment and use of piperazine compounds in the treatment. It should be noted that in the present study, whenever Ascarids were seen at the autopsy, it was recorded irrespectively whether it was the primary cause or not of the condition causing death. Hence the incidence of Ascaridiasis shown does not reflect the actual incidence of the disease due to Ascaridiasis.

Marek's Disease was not seen in 1975. Kulasegaram ${ }^{5}$ recorded several outbreaks in 1974 while no cases were seen upto 1973. In this study it was observed in 1976 and the incidence went up in the later years.

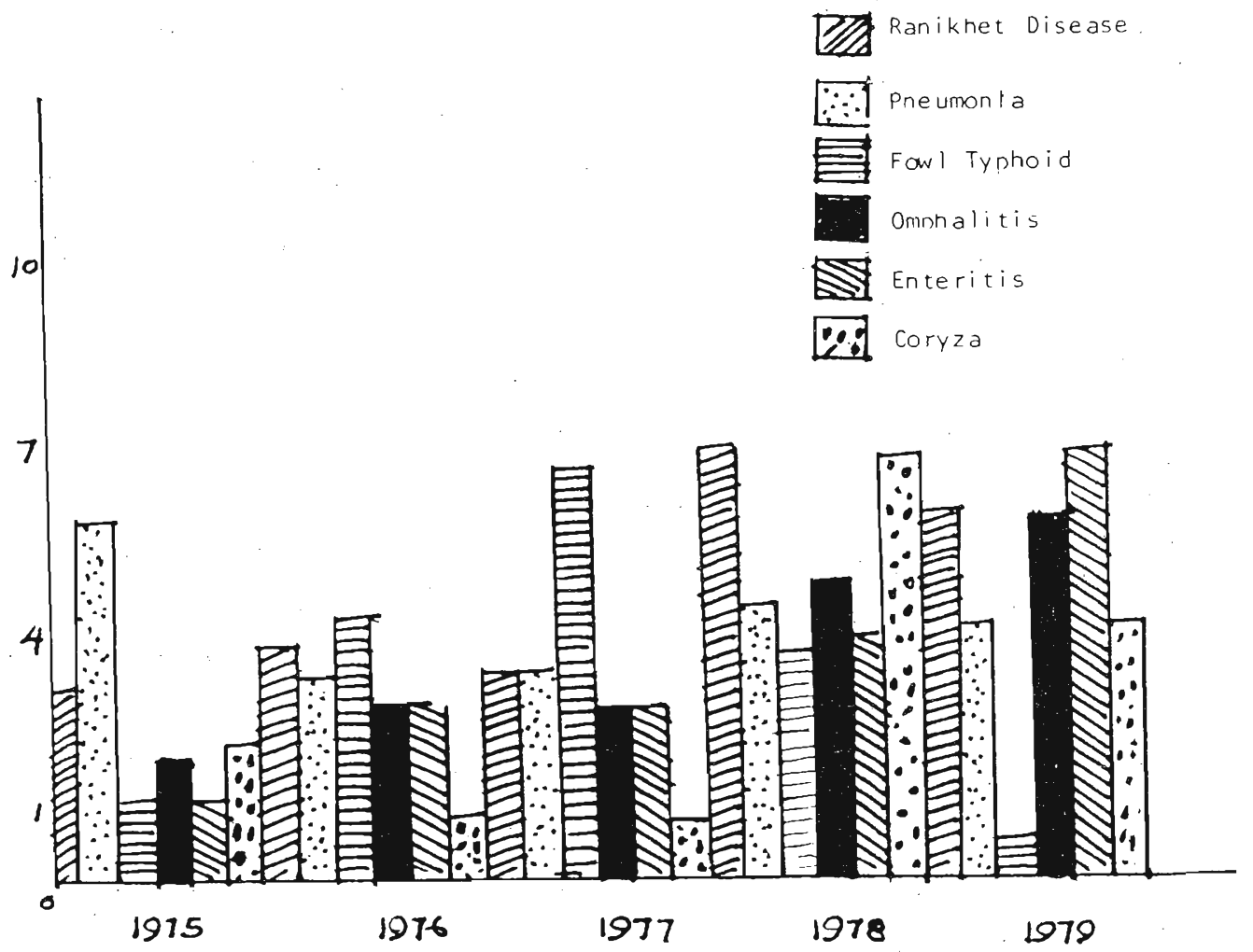

Fin. 2. Diseases of moderate incidence. 


\subsection{Diseases And Disease Conditions of Moderate Incidence}

Figure 2 shows the distribution of the diseases.

Once a major disease in poultry in this country causing heavy mortality, Ranikhet Disease had only a moderate incidence and the average incidence was $4.9 \%$. Kulasegaram ${ }^{5}$ who reported high incidence of $12 \%$ to $10 \%$ in 1960 and 1961 respectively. The disease was seen only in nonvaccinated birds.

Pneumonia due to non specific causes such as the result of lowering of resistance in case of Vitamin A deficiency, poor management and feeding was recorded quite uniformly throughout the period.

Fowl Typhoid was suspected in $4.4 \%$ cases in 1976 and in $3.8 \%$ in 1978 , though this condition was not recorded in this country earlicr, there was sufficient evidence to suspect this condition.

Omphalitis showed a steady increase in incidence from 1975 to 1979. This may be due to increase in number of hatcheries that had come up to supply the great demand for chicks and the management and the hygienic practices in these hatcheries were not upto the required standard.

Infectious Coryza due to Haemophilus gallinarum, showed a lower incidence at the beginning but showed a steady increase from 1975 to 1979 . In Kulasegaram's study ${ }^{5}$ it was the most predominant type of respiratory disease. This is probably due to climatic differences of the two regions.
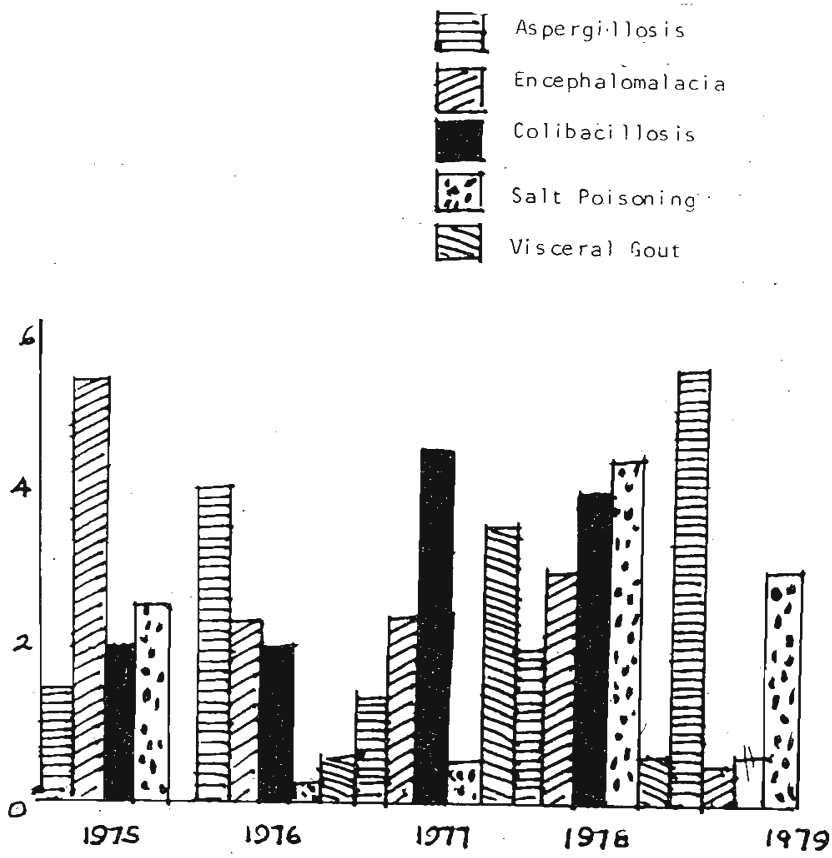

Fig. 3. Diseases, of low incidence. 


\subsection{Diseases And Disease Conditions of Low Incidence}

Figure 3 shows the distribution of diseases of low incidence.

Aspergillosis showed a steady increase in incidence during the five year period. Though there was a fairly high incidence of Encephalomalacia at the beginning of the period, it reached lower levels during the latter periods. This may be attributed to the fact that the poultry feed was not stored for a long time so as to prevent the destruction of Vitamin $\mathrm{E}$ in it as there was a great demand for poultry feed towards the end of this period of study.

Incidence of Colibacillosis gradually increased till 1978. But no cases were recorded in 1979. Most commonly affected were the birds in the four to six months of age and the usual complaint was that one or two birds died every week. The characteristic lesion seen at the autopsy was perihepatitis with a gelatinous covering of the liver and fibrino-gelatinous material surrounding the heart due to pericarditis. Response to Furazolidone treatment was very satisfactory.

A fluctuating increase of salt poisoning was seen throughout this period. This condition was mainly caused by use of 'dry fish' powder which has high salt content as a source of fish meal in the ration.

\subsection{Diseases And Disease Conditions of Very Low Incidence}

These include diseases below $1 \%$ incidence and most of these conditions were not recorded throughout the period of study. They are generally considered to be less important except for two conditions, Intussusception of Intestine that recorded incidence of $3.0 \%$ in 1975 and $1.7 \%$ in 1976 and Chronic Peritonitis that recorded $2.6 \%$ in 1979. Intussusception of intestine has never been reported as an outbreak, but only as isolated cases. But this condition was reported as outbreaks in six poultries in $1975^{15}$ due to feeding of young birds with $10-15 \%$ raw ox blood mixed in poultry mash as a source of protein. 
Table 2 - LIST OF POULTRY DISEASES AND DISEASE CONDITIONS AND INCIDENCE RECORDED FOR 5 YEARS PERIOD $(1975-1979)$

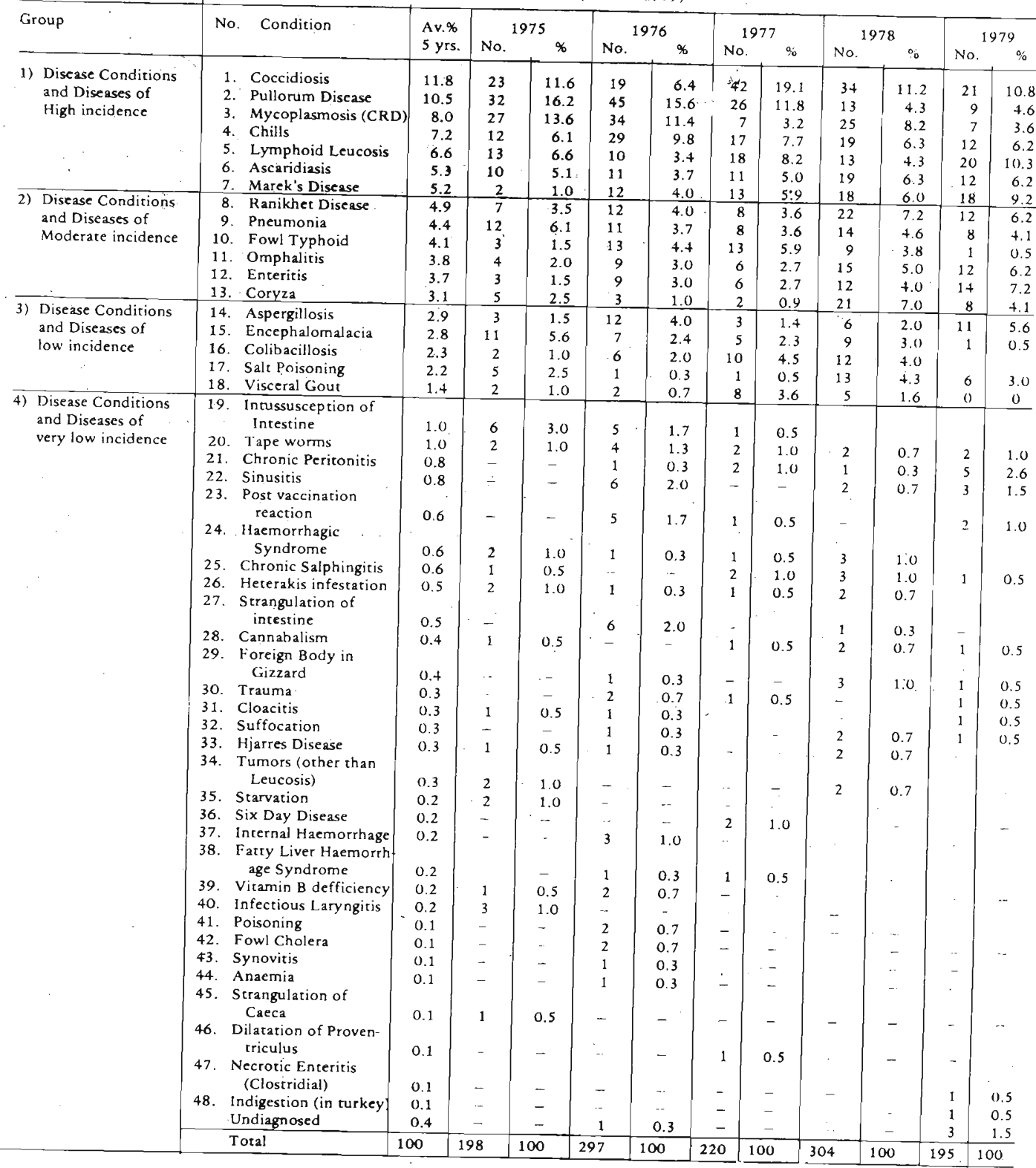




\section{References:}

1. BANDARANAYAKE, A (1953) An Outbreak of Listeriosis in Gooslings. Ceylon Vet. J. $1: 40$.

2. BANDARANAYAKE, A. (1954) Coligranuloma (Hjarres Disease) Of Fowls. Ceylon Vet. J. 2: 21 .

3. CARTER, G. R. (1973) Diagnostic Procedures In Veterinary Microbiology.

4. KULASEgARAM, P. (1977 Salmonellosis In Poultry in Ceylon. Ceylon Vet. J. 11:60

5. KULASEGARAM, P. (1975) An Analysis of the records of post mortem examinations carried out in chickens between 1960-1974. Ceylon Vet. J., vol. 23, nos. 3 \& 4.

6. Kulasegaram, P., Wettimuny, S. G. de S., \& SEneviratne, P. (1969). Avian Encephalomyelitis Infection In Ceylon. Ceylon Vet. J. $17: 81$.

7. McGaughey, C.A. \& BANDARANAYAKE, A. (1963) Monialiasis in Guinea Fowl Chicks and other poultry. Ceylon Vet. J., $1: 43$.

8. RANAWEERA, K. N. P. (1972) Recognition of Acute Marek's Disease in Ceylon. Ceylon Vet. J., $20: 35$.

9. RASIAH, P. \& KUlASEgaRAM, P. (1972) The pattern of Coccidiosis in Ceylon. Ceylon Vet.J., $20: 96$.

10. SEnEViratNe, P. (1959) Diseases of Poultry In Ceylon. Ceylon Vet. J., $7: 13$.

11. SENEVIRATNE, P. (1959) An outbreak of bird Malaria in a Flock of Domestic Fowls. Ceylon Vet. J., $7: 51$.

12. SEneviratne, P. \& MAHAlingaM, S. (1962) Preliminary Studies In Coccidia In Domestic Fowl In Ceylon. Ceylon Vet. J., $10: 132$.

13. SENEVIRATNe, P., BANDARANAKE, A., DHANAPALA, S. B. (1963) Leucocytozoon Caulleryi Mathis \& Leger Infection in domestic fowls in Ceylon. Ceylon. Vet. J. $11: 2$.

14. SIRIWARDENE, J. A. de S. (1959) Fowl Cholera In Ceylon. Ceylon Vet. J., $7: 10$.

15. WICKRAMASURIYA, U. G. J. S. (1975) Intussussception of intestine of fowl. Vet. Rec., 9:172. 